\title{
EDITORIAL
}

\section{Statins in patients with sepsis and ARDS: is it over? Yes}

\author{
Waleed Alhazzani $i^{1,2}$ and Jonathon Truwit ${ }^{3^{*}}$
}

(C) 2016 Springer-Verlag Berlin Heidelberg and ESICM

\section{Introduction}

Sepsis is associated with significant morbidity and mortality despite advances in treatment, technology and research. Therefore, multiple studies have focused on understanding the pathophysiology of sepsis to improve therapeutic options. We now know that infection triggers an inflammatory response and a compensatory antiinflammatory response that is intended to minimize the damage from infection. In some patients, this inflammatory response could lead to further tissue damage and, subsequently, to multi-organ failure and acute respiratory distress syndrome (ARDS) [1]. Therefore, various immunomodulating and anti-inflammatory agents have been studied in the sepsis population.

\section{Statins: how do they work?}

Statins act by inhibiting 3-hydroxy-3-methylglutaryl coenzyme A (HMG-CoA), and have been used as a lipidlowering agent for many years. However, recent studies have shown that statins have immunomodulation properties that are independent of the lipid-lowering effect.

A randomized trial that enrolled 20 healthy subjects showed that the use of $80 \mathrm{mg}$ of simvastatin for 4 days suppresses the production of high-sensitive C-reactive protein (hsCRP), monocyte chemoattractant protein (MCP-1) and tissue factor (TF), compared to placebo. In addition, simvastatin blunted the increase of monocyte TF expression in response to lipopolysaccharides [2]. Other studies have suggested that statins can inhibit the production of proinflammatory cytokines [3]. An animal

\footnotetext{
*Correspondence: truwit@froedtert.com

${ }^{3}$ Department of Medicine, Pulmonary and Critical Care, Froedtert and Medical College of Wisconsin, Milwaukee, USA

Full author information is available at the end of the article
}

For contrasting viewpoints, please go to doi: 10.1007/s00134-016-4454-9 and doi: 10.1007/s00134-016-4564-4. study showed that simvastatin attenuated the inflammatory response and vascular leak in murine models with sepsis-induced acute lung injury (ALI) [4], which formed the basis for subsequent human trials.

\section{Statins and mortality in sepsis}

Multiple studies have examined the effect of statins on mortality in patients with varying severities of sepsis. Initial observational studies showed promising results, and a meta-analysis of adjusted estimates from 26 observational studies (336,245 patients) showed a significant reduction in mortality with statin use [relative risk (RR) 0.65; $95 \%$ CI 0.57, 0.75] [5]. However, randomized clinical trials (RCTs) failed to show mortality benefit with statins use. A systematic review and a meta-analysis of five RCTs (650 patients) compared statins to placebo in septic patients. Studies used atorvastatin or simvastatin at doses between 10 and $40 \mathrm{mg}$ daily, for varying durations of therapy. Mortality did not differ significantly between the two groups (RR 0.95; 95 \% CI 0.74, 1.21) [6]. However, these results are limited by imprecise estimates and clinical heterogeneity between studies. Subsequently, the largest trial to date (SAILS) randomized patients with sepsis-induced ARDS to receive either rosuvastatin or placebo [7]. The trial was stopped early for futility; 60-day mortality did not differ between the two groups ( 28.5 vs. $24.9 \%$; rosuvastatin and placebo, respectively). Some authors argue that hydrophilic statins, like rosuvastatin, have a reduced mitotoxic effect, and the mitotoxic effect may be paradoxically beneficial in septic patients [8]. However, other RCTs, using lipophilic statins, have failed to show mortality benefit of statin use in patients with ventilator-associated pneumonia, ALI, or ARDS [9-11]. Pooled estimates from RCTs in patients with ARDS showed no mortality benefit of statins (Fig. 1). A more robust individual patient data meta-analysis by Gordon et al. (personal communication) revealed no benefit of statins in ARDS, even 


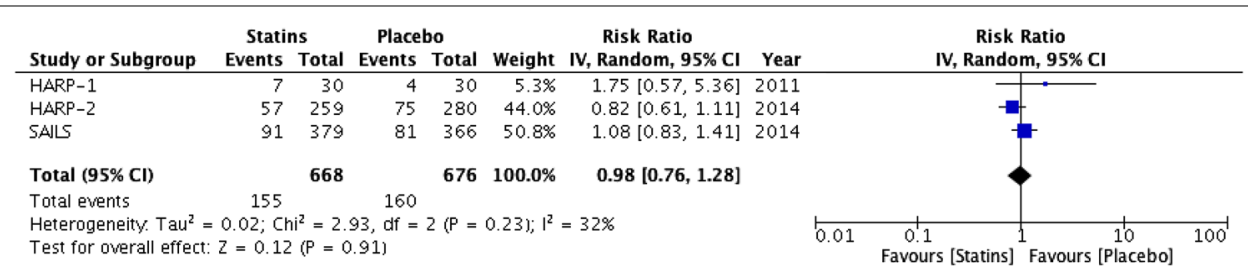

Fig. 1 Meta-analysis using random-effects model to pool the estimates from three RCTs that examined the effect of statin compared to placebo on 28-day mortality in patients with ARDS

when stratified by dosage or lipo/hydrophilic properties. The collective body of evidence from RCTs failed to show mortality benefit of statin therapy in sepsis.

\section{Statins and cognitive impairment in sepsis}

A prospective observational study showed that statin use was associated with reduction in the odds of developing delirium in septic patients [12]. This profound treatment effect was not reproducible in a subsequent higher quality study. The SAILS investigator did not find a significant reduction in delirium risk with statin use [13]. This discrepancy in the results could be explained by differences in study design, use of rosuvastatin which has lower penetration to the central nervous system, or differences in the duration of exposure to the intervention or ineffectiveness of statins in preventing delirium. It remains unclear whether statins can lower the risk of delirium in septic patients.

\section{Statins and long-term outcomes in sepsis}

Several studies have investigated the impact of statins on cognitive and physical functions in septic patients. Recently, two sub-studies of the SAILS Trial reported long-term outcomes in a subset of patients. Rosuvastatin and placebo groups did not differ in the risk of 6and 12-month cognitive impairment [13]. Furthermore, 1-year survival, physical function, and mental health did not differ between the two groups [14]. Therefore, it appears that statins do not have an important effect on long-term outcomes in this population.

\section{Statins and adverse events}

Statin use can lead to hepatic and skeletal muscle toxicity, the incidence of side effects depending on the type and dose of statin. In the SAILS Trial, the rosuvastatin group was associated with a small but significant reduction in liver and kidney failure-free days (i.e. resulted in more organ dysfunction) [7]. Another RCT in critically ill patients with ARDS showed significantly higher hepatic transaminases and creatine kinase (CK) levels in the simvastatin group; however, serious adverse events did not differ betweenthe groups [11].

\section{Conclusion}

There is a clear discrepancy between the results of observational studies and RCTs, and it is likely that observational studies resulted in inflated and biased estimates. Even with robust statistical methods, confounders remain a limitation of observational studies [15]; therefore, observational data should be considered hypothesisgenerating and not practice-changing. The current RCTs failed to show significant benefit. In addition, the pharmacokinetics of statins is altered in critically ill patients, which may potentiate adverse events.

It is possible that a subset of patients may benefit from the pleotropic effect of statins, or that higher dosing maybe more effective (at the expense of potential side effects). Future studies could focus on identifying the target population, the most effective agent, and appropriate dosing. However, such studies would be diverting resources away from other promising therapies. Until more evidence is available, the routine use of statins to treat sepsis or ARDS is not justified.

\section{Author details \\ 1 Department of Medicine, Division of Critical Care, McMaster University, Hamilton, Canada. ${ }^{2}$ Department of Clinical Epidemiology and Biostatistics, McMaster University, Hamilton, Canada. ${ }^{3}$ Department of Medicine, Pulmonary and Critical Care, Froedtert and Medical College of Wisconsin, Milwaukee, USA.}

Compliance with ethical standards

Conflicts of interest

None

Received: 26 September 2016 Accepted: 28 September 2016 Published online: 17 October 2016

References

1. Angus DC, van der Poll T (2013) Severe sepsis and septic shock. N Engl J Med 369:840-851

2. Steiner S, Speidl WS, Pleiner J, Seidinger D, Zorn G, Kaun C, Wojta J, Huber K, Minar E, Wolzt M, Kopp CW (2005) Simvastatin blunts endotoxininduced tissue factor in vivo. Circulation 111:1841-1846

3. Arnaud C, Burger F, Steffens S, Veillard NR, Nguyen TH, Trono D, Mach F (2005) Statins reduce interleukin-6-induced C-reactive protein in human hepatocytes: new evidence for direct antiinflammatory effects of statins. Arterioscler Thromb Vasc Biol 25:1231-1236 
4. Jacobson JR, Barnard JW, Grigoryev DN, Ma SF, Tuder RM, Garcia JG (2005) Simvastatin attenuates vascular leak and inflammation in murine inflammatory lung injury. Am J Physiol Lung Cell Mol Physiol 288:L1026-L1032

5. Wan YD, Sun TW, Kan QC, Guan FX, Zhang SG (2014) Effect of statin therapy on mortality from infection and sepsis: a meta-analysis of randomized and observational studies. Crit Care 18:R71

6. Pasin L, Landoni G, Castro ML, Cabrini L, Belletti A, Feltracco P, Finco G, Carozzo A, Chiesa R, Zangrillo A (2013) The effect of statins on mortality in septic patients: a meta-analysis of randomized controlled trials. PLOS ONE 8:e82775

7. National Heart L, Blood Institute ACTN, Truwit JD, Bernard GR, Steingrub J, Matthay MA, Liu KD, Albertson TE, Brower RG, Shanholtz C, Rock P, Douglas IS, deBoisblanc BP, Hough CL, Hite RD, Thompson BT (2014) Rosuvastatin for sepsis-associated acute respiratory distress syndrome. N Engl J Med 370:2191-2200

8. Morel J, Singer M (2014) Statins, fibrates, thiazolidinediones and resveratrol as adjunctive therapies in sepsis: could mitochondria be a common target? Intensive Care Med Exp 2:9

9. Papazian L, Roch A, Charles PE, Penot-Ragon C, Perrin G, Roulier P, Goutorbe P, Lefrant JY, Wiramus S, Jung B, Perbet S, Hernu R, Nau A, Baldesi O, Allardet-Servent J, Baumstarck K, Jouve E, Moussa M, Hraiech S, Guervilly C, Forel JM, Group S-VS (2013) Effect of statin therapy on mortality in patients with ventilator-associated pneumonia: a randomized clinical trial. JAMA 310:1692-1700

10. Craig TR, Duffy MJ, Shyamsundar M, McDowell C, O'Kane CM, Elborn JS, McAuley DF (2011) A randomized clinical trial of hydroxymethylglutarylcoenzyme a reductase inhibition for acute lung injury (The HARP Study). Am J Respir Crit Care Med 183:620-626
11. McAuley DF, Laffey JG, O'Kane CM, Perkins GD, Mullan B, Trinder TJ, Johnston P, Hopkins PA, Johnston AJ, McDowell C, McNally C, Investigators $\mathrm{H}$-, Irish Critical Care Trials G (2014) Simvastatin in the acute respiratory distress syndrome. N Engl J Med 371:1695-1703

12. Morandi A, Hughes CG, Thompson JL, Pandharipande PP, Shintani AK, Vasilevskis EE, Han JH, Jackson JC, Laskowitz DT, Bernard GR, Ely EW, Girard TD (2014) Statins and delirium during critical illness: a multicenter, prospective cohort study. Crit Care Med 42:1899-1909

13. Needham DM, Colantuoni E, Dinglas VD, Hough CL, Wozniak AW, Jackson JC, Morris PE, Mendez-Tellez PA, Ely EW, Hopkins RO (2016) Rosuvastatin versus placebo for delirium in intensive care and subsequent cognitive impairment in patients with sepsis-associated acute respiratory distress syndrome: an ancillary study to a randomised controlled trial. Lancet Respir Med 4:203-212

14. Dinglas VD, Hopkins RO, Wozniak AW, Hough CL, Morris PE, Jackson JC, Mendez-Tellez PA, Bienvenu OJ, Ely EW, Colantuoni E, Needham DM (2016) One-year outcomes of rosuvastatin versus placebo in sepsisassociated acute respiratory distress syndrome: prospective follow-up of SAILS randomised trial. Thorax 71:401-410

15. Zhang Z, Ni H, Xu X (2014) Do the observational studies using propensity score analysis agree with randomized controlled trials in the area of sepsis? J Crit Care 29:886 (e889-815) 